in vivo $34: 2883-2889(2020)$

doi:10.21873/invivo.12116

\title{
Proton Therapy for Primary Renal Cell Carcinoma: The First Nationwide Retrospective Study in Japan
}

\author{
NOBUYOSHI FUKUMITSU ${ }^{1}$, HITOSHI ISHIKAWA ${ }^{2,3}$, TAKESHI ARIMURA $^{4}$, HITOSHI WADA ${ }^{5}$, \\ TOMOAKI OKIMOTO $^{6}$, YOSHITAKA SATO ${ }^{7}$, HIROMITSU IWATA ${ }^{8}$, SHOSEI SHIMIZU $^{2}$ and HIDEYUKI SAKURAI ${ }^{2}$ \\ ${ }^{1}$ Department of Radiation Oncology, Kobe Proton Center, Hyogo, Japan; \\ ${ }^{2}$ Department of Radiation Oncology, University of Tsukuba, Faculty of Medicine, Ibaraki, Japan; \\ ${ }^{3}$ National Institutes for Quantum and Radiological Science and Technology, QST Hospital, Chiba, Japan; \\ ${ }^{4}$ Medipolis Proton Therapy and Research Center, Kagoshima, Japan; \\ ${ }^{5}$ Department of Radiation Oncology, Southern Tohoku Proton Therapy Center, Fukushima, Japan; \\ ${ }^{6}$ Department of Radiology, Hyogo Ion Beam Medical Center, Hyogo, Japan; \\ ${ }^{7}$ Proton Therapy Center, Fukui Prefectural Hospital, Fukui, Japan; \\ ${ }^{8}$ Departments of Radiation Oncology, Nagoya City West Medical Center, Aichi, Japan
}

\begin{abstract}
Background/Aim: This multi-institutional study aimed to investigate the efficacy and feasibility of proton beam therapy (PBT) for renal cell carcinoma (RCC) in Japan. Patients and Methods: The survival, local control, and toxicities in 22 RCC patients treated between 2001 and 2016 at 6 Japanese PBT institutes were analyzed. Results: The 22 patients comprised 20 men and had a median age of 67 (range $=42-88$ ) years. The total irradiation dose was 6079.6 Gy (relative biological effectiveness). Over a median follow-up of 37 months, the 3-year overall and diseasespecific survival rates were $95 \%$ and $100 \%$, respectively, and no recurrence occurred. No patient experienced grade 3 or higher adverse events. The serum blood urea nitrogen $(p=0.25)$ and creatinine levels $(p=0.95)$ were not significantly affected, although the mean estimated glomerular filtration rate was reduced by $7.1 \pm 11.2$ $\mathrm{ml} / \mathrm{min} / 1.73 \mathrm{~m}^{2}$. Conclusion: Despite the small number of patients, high-dose PBT can control RCC while maintaining their renal function with high probability, and could be and alternative curative therapy especially for inoperable patients.
\end{abstract}

This article is freely accessible online.

Correspondence to: Hitoshi Ishikawa, MD, Ph.D., National Institutes for Quantum and Radiological Science and Technology, QST Hospital, 4-9-7 Anagawa, Inage, Chiba 263-8555, Japan. Tel: +81 432063306, Fax: +81 2063345, e-mail: ishikawa.hitoshi@qst.go.jp

Key Words: Renal cell carcinoma, proton beam therapy, local control, toxicity, radiotherapy.
The incidence of renal cancer continues to increase. In Japan, there were approximately 25,000 estimated new cases of renal cancers, according to the Cancer Registry and Statistics, in 2015 (1), and renal cell carcinoma (RCC) accounts for the majority of these cancers. RCC predominantly affects the older population and males.

The standard therapy for patients with RCC is surgery (2, 3). Surgical treatment usually involves removing either the tumor (partial nephrectomy) or the entire kidney and surrounding tissues (radical nephrectomy). Alternative treatments are used for patients deemed ineligible for surgery and for whom active surveillance is an inappropriate treatment choice. Radiofrequency ablation involves either percutaneous or intraoperative insertion of electrodes to induce thermal ablation in the tumor (4). Cryoablation delivered via a laparoscopic approach involves supercooled liquid introduced to create an ice ball, which causes ablation (5). Both these treatments are invasive, requiring access to the kidney via percutaneous incisions, and are problematic for patients who require continuous anticoagulative medications.

RCC has traditionally been regarded as radioresistant, yet a pathological complete response after radiotherapy (RT) has been reported $(6,7)$. A few clinical studies have reported benefits of stereotactic body RT (SBRT) on RCC outcomes, such as high local tumor control and few adverse events (810). A systematic review showed that SBRT is comparable with radiofrequency ablation or cryotherapy in terms of local effectiveness, with a local progression rate of $6.1 \%$ (11). RT is occasionally used to treat RCC patients, especially those who prefer a non-invasive procedure or who have a tumor size beyond the range of alternative treatments.

Regarding particle beam therapy, carbon ion RT showed 5 -year and 10-year overall survival (OS) rates of $89.2 \%$ and 
$58.7 \%$ in 19 patients, respectively (12). Proton beam therapy (PBT), which is another type of particle beam therapy, has since long been used to treat various cancers (13-16), but there are no clinical reports of its use for RCC. Because the numbers of RCC patients treated with PBT at a single institution are very small and thus the data from a single institution are insufficient for evaluation, we conducted a multi-institutional study in Japan to assess the treatment effects and toxicities of PBT in RCC patients.

\section{Patients and Methods}

A retrospective observational study of patients who underwent PBT for their primary RCCs at six Institutions was conducted. The participating Institutions at which PBT was used between 2001 and 2016 were Medipolis Proton Therapy and Research Center, University of Tsukuba Hospital, Southern TOHOKU Proton Therapy Center, Hyogo Ion Beam Medical Center, Nagoya City West Medical Center, and Fukui Prefecture Hospital. The present study was approved by the institutional review board of each institution (no. 31-3). The clinical information of each patient was anonymized and collected using an electronic data capture system.

A total of 22 patients who received PBT for histologically (including cytologically) diagnosed or clinically diagnosed RCC from January 2001 to December 2016 were enrolled. Exclusion criteria were the presence of any metastasis or having received palliative treatment. The clinical diagnosis of RCC was based on radiographic findings. The relative biological effectiveness (RBE) was calculated as 1.1 and the biological effective dose (BED) was calculated using the linear-quadratic model (17). The BED was defined as $n d(1+d / \alpha / \beta)$, where $n$ is the fractionation number, $d$ is the daily dose, and the $\alpha / \beta$ ratio is $10 \mathrm{~Gy}$ for RCC and $3 \mathrm{~Gy}$ for the normal kidney.

The follow-up period was defined from the first day of PBT to the date of death or the last follow-up visit. Principally, patients were followed up at 6-month intervals after PBT. The OS and disease-specific survival rates were calculated from the first day of PBT to the date of the event or the last follow-up visit using the Kaplan-Meier method. Local tumor control was classified as a complete response, partial response, stable disease, or progressive disease according to the Response Evaluation Criteria in Solid Tumors, version 1.1 (18). Radiation-related toxicities were assessed based on the National Cancer Institute's Common Terminology Criteria for Adverse Events, version 4.0 (19). Renal function was estimated by measuring the serum blood urea nitrogen (BUN) level, creatinine $(\mathrm{Cr})$ level, and estimated glomerular filtration rate (eGFR) before PBT and at the last follow-up.

\section{Results}

Of the 22 patients, $20(91 \%)$ were men, and $2(9 \%)$ were women, and the median age was 67 (range=42-88) years. Table I shows the patient characteristics. The total irradiation dose was 60-79.6 Gy (relative biological effectiveness [RBE]) delivered in 10-36 fractions and the BEDs of RCC ranged from 93.9 to $109.6 \mathrm{~Gy}$ (median: $104.9 \mathrm{~Gy}$ ). The median follow-up period was 37 (range=22-82) months. A
Table I. Characteristics of patients with renal cell carcinoma.

\begin{tabular}{lr}
\hline Age [median 67 (range=42-88)], years & \\
$<69$ & 15 \\
$\geq 70$ & 7 \\
Gender & 20 \\
Male & 2 \\
Female & \\
T stage & 17 \\
T1a & 3 \\
T1b & 1 \\
T2 & 1 \\
T3 & \\
Location & 13 \\
Right & 9 \\
Left & \\
Tumor size $[$ median 35 (range=12-73)], mm & 16 \\
$<40$ & 6 \\
$\geq 40$ & 11 \\
Dose fractionation, Gy (RBE)/fr & 1 \\
$60.0 \mathrm{~Gy} / 10 \mathrm{fr}$ & 3 \\
$66.0 \mathrm{~Gy} / 10 \mathrm{fr}$ & 1 \\
$71.6 \mathrm{~Gy} / 16 \mathrm{fr}$ & 1 \\
$72.6 \mathrm{~Gy} / 22 \mathrm{fr}$ & \\
$76.0 \mathrm{~Gy} / 20 \mathrm{fr}$ & 1 \\
$77.0 \mathrm{~Gy} / 35 \mathrm{fr}$ & \\
$79.2 \mathrm{~Gy} / 22 \mathrm{fr}$ & \\
$79.6 \mathrm{~Gy} / 36 \mathrm{fr}$ & \\
\hline
\end{tabular}

Gy (RBE)/fr: Gray (relative biological effectiveness)/fraction.

total of 21 patients survived until the last follow-up, whereas the remaining patient died of a thoracic aortic dissection at 16 months after PBT without any signs of RCC recurrence or PBT-related toxicities. The 3-year OS and disease-specific survival rates were $94.7 \pm 10.0 \%$ and $100 \%$ at 3 years (Figure $1)$.

No recurrence was observed in the present study. Tumor shrinkage after PBT usually occurred gradually (Figure 2). The local response at the last follow-up was defined as a complete response, a partial response, stable disease, and progressive disease in $1,9,10$, and 0 patients, respectively; the response was unknown in 2 patients (Table II). The respective numbers in the 16 tumors $<4 \mathrm{~cm}$ in diameter were $1,7,6$, and 0 , and those in the remaining 6 tumors $\geq 4 \mathrm{~cm}$ in diameter were $0,2,4$, and 0 (Table II).

Grade 2 or higher adverse events were observed in one patient during the acute phase (dermatitis) and two patients during the late phase (renal dysfunction at 9 and 28 months after PBT, respectively). The serum blood urea nitrogen (BUN) level, creatinine (Cr) level, and estimated glemerular filtration rate (eGFR) were $17.1 \pm 7.0 \mathrm{mg} / \mathrm{dl}, 1.4 \pm 1.6 \mathrm{mg} / \mathrm{dl}$, and $62.2 \pm 1.6 \mathrm{ml} / \mathrm{min} / 1.73 \mathrm{~m}^{2}$, respectively, at the start of PBT and $19.4 \pm 9.3 \mathrm{mg} / \mathrm{dl}, 1.4 \pm 1.2 \mathrm{mg} / \mathrm{dl}$, and $55.0 \pm 24.8 \mathrm{ml} / \mathrm{min} / 1.73$ $\mathrm{m}^{2}$, respectively, at the last follow-up examination (Figure 3 ). The serum BUN and Cr levels were not significantly increased 


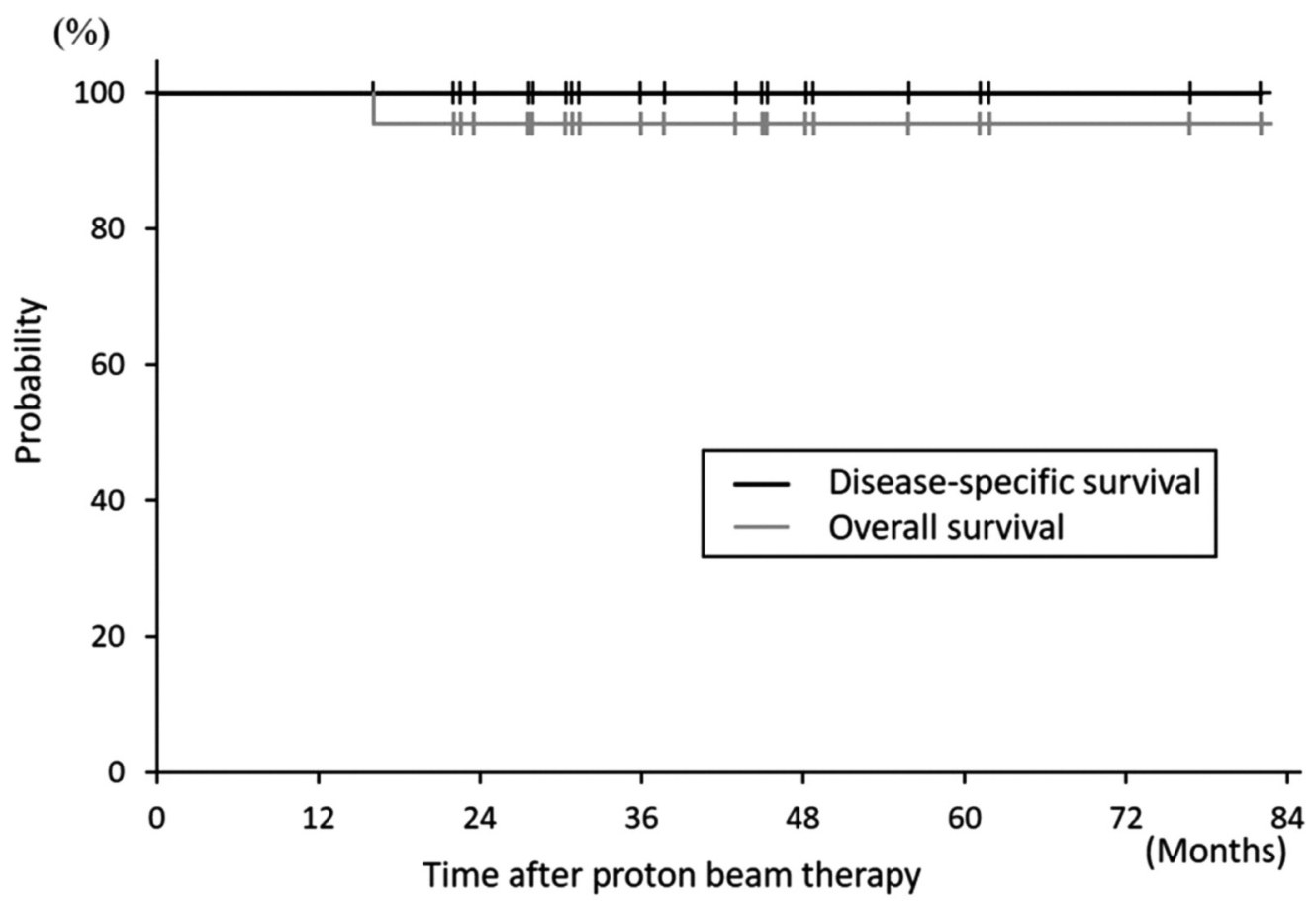

Figure 1. Kaplan-Meier curves for overall and disease-specific survival.

compared to baseline ( $p=0.25$ and $p=0.95$, respectively). The serum eGFR after PBT did not decrease at less than $50 \%$ of baseline levels in any patient, although the mean decrease after treatment was significant $(p=0.007)$.

\section{Discussion}

There are very few scientific reports on RCC treated with RT and even fewer on RCC treated with PBT. The principal reason is probably the small number of such cases within a single facility. We conducted a nationwide study involving all PBT facilities in Japan. As a result, we collected data from 22 patients with RCC treated with PBT from multiple institutions, and these data were sufficient for analyzing the efficacy of PBT on primary RCC as a curative intent, although the sample size was still small. To the best of our knowledge, this is the first report to evaluate the effect of PBT in RCC patients.

Adverse events were found in one patient in the acute phase and two patients in the late phase. However, these events were grade 2, and no severe (grade 3 or higher) adverse events were observed in any patient. To assess renal function, changes in the serum BUN levels, Cr levels, and eGFR were measured in blood samples. The results indicated no significant increase of the BUN or $\mathrm{Cr}$ level after ipsilateral irradiation of the RCC (Figure 3). Regarding the eGFR, the greatest change observed was from $93 \mathrm{ml} / \mathrm{min} / 1.73 \mathrm{~m}^{2}$ before
PBT to $55.5 \mathrm{ml} / \mathrm{min} / 1.73 \mathrm{~m}^{2}$ at the last follow-up. However, the change in the remaining patients was relatively small; the mean eGFR reduction was $7.1 \pm 11.2 \mathrm{ml} / \mathrm{min} / 1.73 \mathrm{~m}^{2}$ over a median follow-up of $>3$ years and there were no grade 3 renal toxicities or need for hemodialysis. Siva et al. evaluated changes in renal function after photon SBRT for RCC in a prospective trial, which included a similar number of patients $(n=21)$ to that in our study (9). They reported that eGFR gradually decreased after SBRT, with a reduction of $8.7 \pm 13.4$ $\mathrm{ml} / \mathrm{min} / 1.73 \mathrm{~m}^{2}$ at 1 year. Similarly, the $\mathrm{Cr}$ levels significantly increased at 1 year post SBRT compared with the baseline level $(p=0.02)$. In their study, there were exponential decreases in the GFR in the affected kidney of $39 \%$ at a dose of $26 \mathrm{~Gy} /$ fraction and of $25 \%$ at $42 \mathrm{~Gy} / 3$ fractions for every $10 \mathrm{~Gy}$ of physical dose delivered (9). Correa et al. reported the latest systematic review of RT for RCC and showed a rate of grade $3 / 4$ adverse events of $1.5 \%$ and an eGFR reduction of $7.7 \mathrm{ml} / \mathrm{min}$ after using mainly photon SBRT (10). On the other hand, Kasuya et al. reported that renal function after carbon ion RT was maintained in all 14 patients evaluated, without pre-treatment definitive renal comorbidities, and the average reduction in the eGFR was $6.1 \mathrm{ml} / \mathrm{min} / 1.73 \mathrm{~m}^{2}$ (12). Taken together, PBT can be used without inflicting any severe damage to the body, including renal function, and appears to be sufficiently safe.

In the present study, a relatively high $\mathrm{BED}_{10}$ ranging from 93.9 to $109.6 \mathrm{~Gy}$ was delivered irrespective of the patient or 


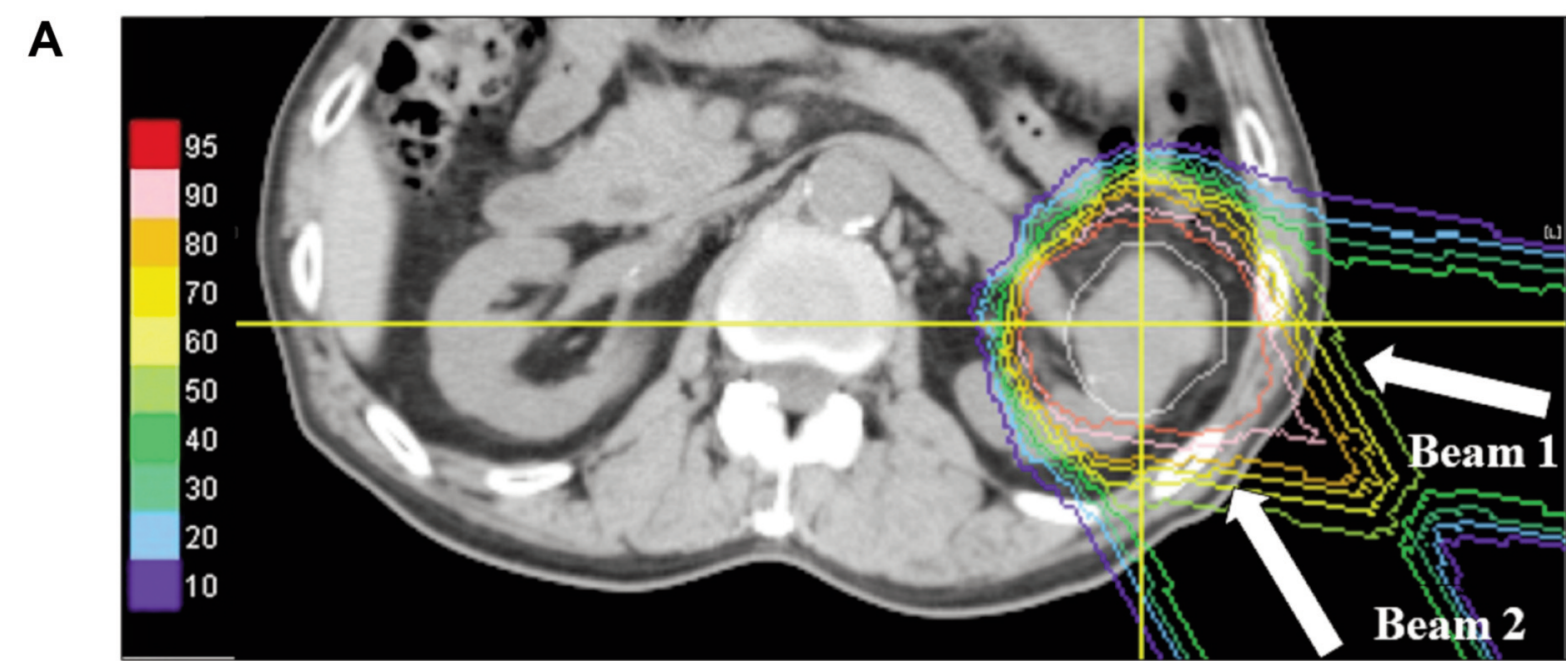

B

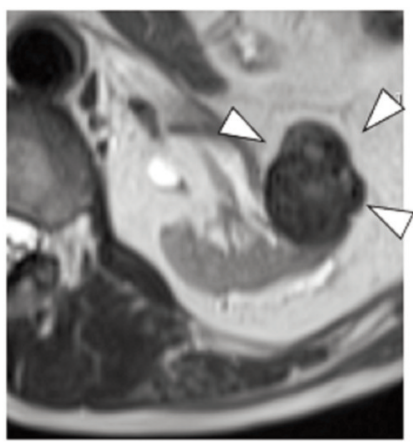

C

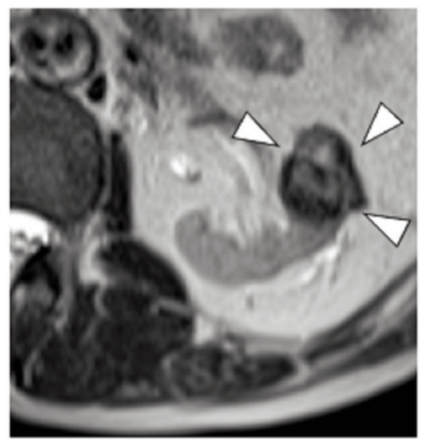

D

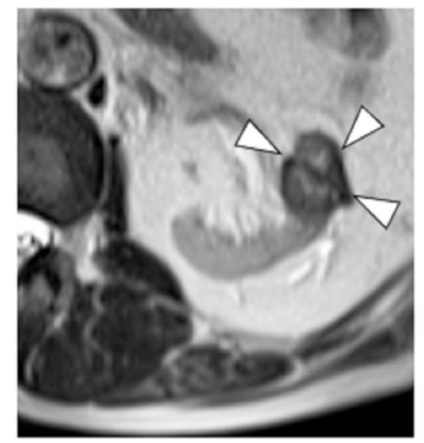

E

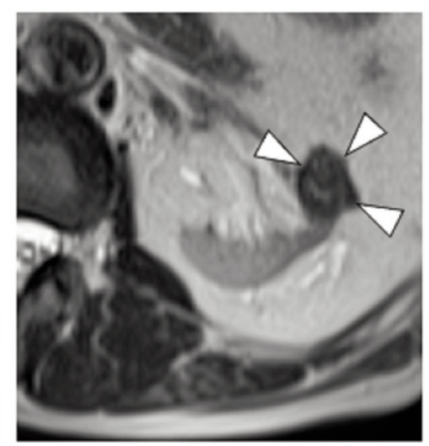

Figure 2. A representative case of renal cell carcinoma after proton beam therapy. Dose distribution of proton beam therapy (a) and changes in a tumor observed on MRI at $18(\mathrm{~b}), 24(\mathrm{c}), 30(\mathrm{~d})$, and $36(\mathrm{e})$ months after treatment.

tumor background characteristics, and neither local progression nor severe toxicity was observed. Kasuya et al. also suggested that a higher BED delivered to the tumor might yield a better local control rate and recommended a higher dose of $72 \mathrm{~Gy}$ (RBE)/16 fractions, corresponding to a $\mathrm{BED}_{10}$ of $104 \mathrm{~Gy}$. Since RCC is generally considered a radioresistant tumor, dose escalation may be a reasonable approach to improve outcomes. However, an analysis of nine international multi-institutional studies of SBRT using a $\mathrm{BED}_{10}$ range of $80-87.5$ Gy reported a 4-year local control rate of $97.8 \%$ (20). Table III summarizes the clinical outcomes of previous studies evaluating RT for primary RCC $(8,11,12,22-25)$. Those studies used a wide range of dose fractionation schedules and $\mathrm{BED}_{10}$ values (range $=38-125$ Gy), but local tumor control was achieved in almost all patients irrespective of the $\mathrm{BED}_{10}$.

On the other hand, a recent systematic review (10) showed a local control rate after SBRT of 97.2\% (95\% CI=93.999.5), and a higher rate of local failure in the low-dose arm compared with the high-dose group or after a dose reduction
Table II. Response of primary renal cell carcinoma to proton beam therapy.

\begin{tabular}{lccccc}
\hline & $\mathrm{CR}$ & $\mathrm{PR}$ & $\mathrm{SD}$ & $\mathrm{PD}$ & Unknown \\
\hline All $(\mathrm{n}=22)$ & 1 & 9 & 10 & 0 & 2 \\
\hline & $(5 \%)$ & $(41 \%)$ & $(45 \%)$ & $(0 \%)$ & $(9 \%)$ \\
Small tumors $(\mathrm{n}=16)$ & 1 & 7 & 6 & 0 & 2 \\
$(<4 \mathrm{~cm}$ in diameter $)$ & $(6 \%)$ & $(44 \%)$ & $(38 \%)$ & $(0 \%)$ & $(12 \%)$ \\
$\begin{array}{l}\text { Large tumors }(\mathrm{n}=6) \\
(\geq 4 \mathrm{~cm} \text { in diameter })\end{array}$ & 0 & 2 & 4 & 0 & 0 \\
& $(0 \%)$ & $(33 \%)$ & $(67 \%)$ & $(0 \%)$ & $(0 \%)$ \\
\hline
\end{tabular}

CR: Complete response; PR: partial response; SD: stable disease; PD: progressive disease.

to mitigate toxicity $(8,10,26)$. Furthermore, the studies using a $\mathrm{BED}_{10}$ range of $60-80$ Gy with a median follow-up for $\geq 2$ years reported a relatively low local control rates (range $=85.7-89 \%$ ) as shown in Table III $(24,25)$. Conversely, local control rates in all the 3 studies and the 


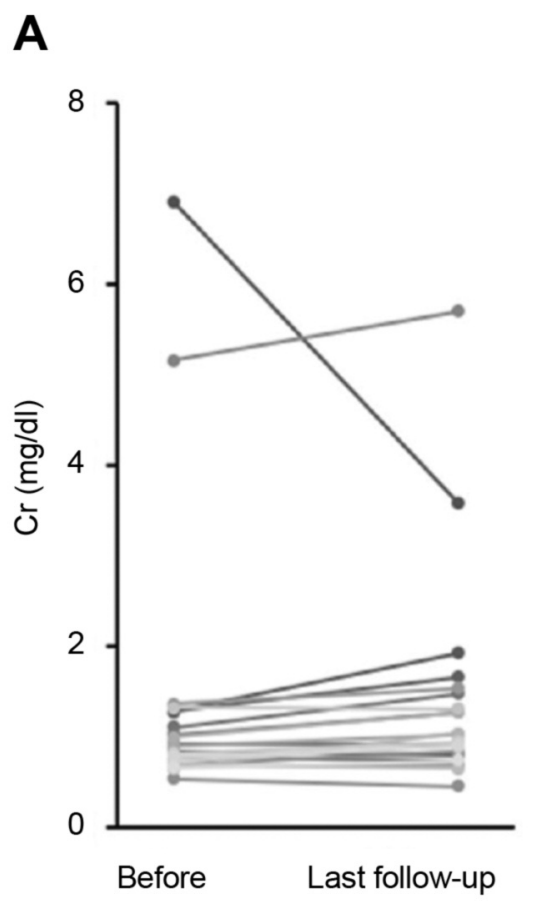

B
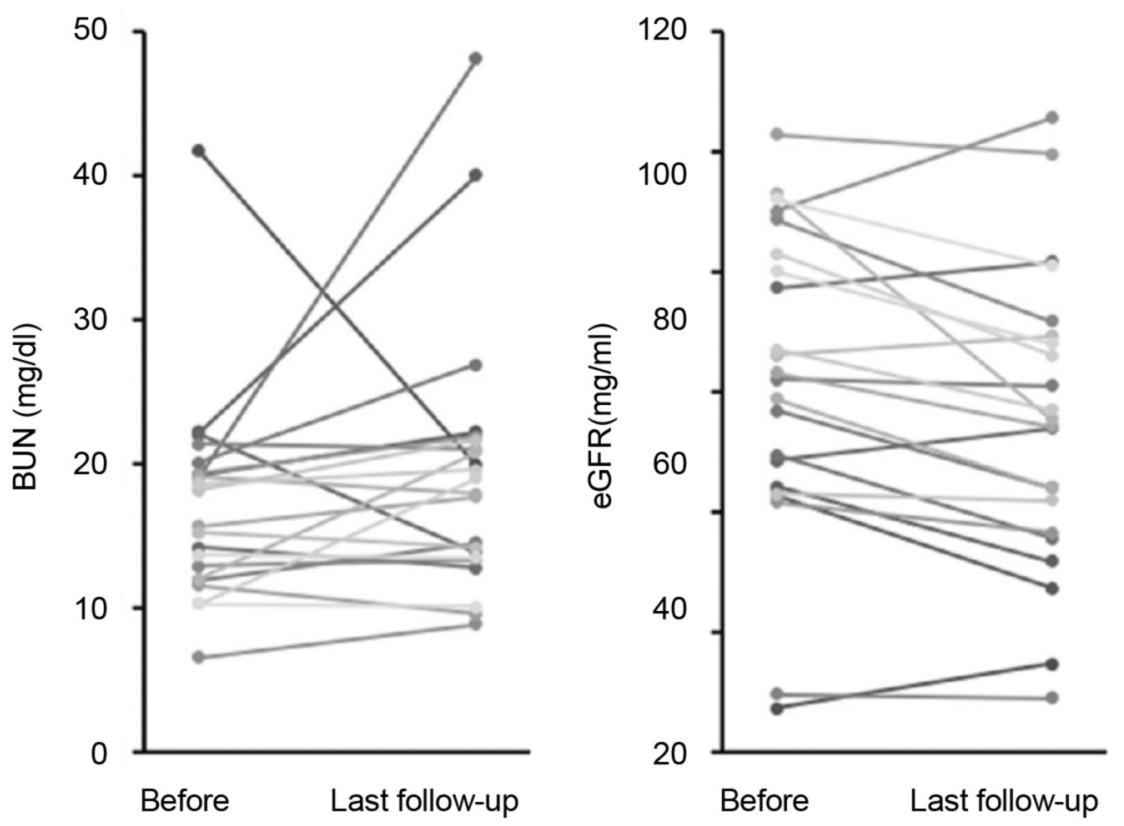

Figure 3. Changes in renal function before and after proton beam therapy. The serum blood urea nitrogen (BUN) levels (a), creatinine (Cr) levels (b), and estimated glomerular filtration rate $(e G F R)(c)$ before proton beam therapy and at the last follow-up, are shown.

Table III. Local control rates according to different irradiation doses for primary renal cell carcinoma.

\begin{tabular}{|c|c|c|c|c|c|c|c|c|}
\hline \multirow{2}{*}{$\begin{array}{l}\text { Ref. } \\
\text { no. }\end{array}$} & \multirow{2}{*}{$\begin{array}{l}\text { No. of } \\
\text { pts. }\end{array}$} & \multirow{2}{*}{$\begin{array}{c}\text { Size } \\
\left(\mathrm{cm} \text { or } \mathrm{cm}^{3}\right)\end{array}$} & \multirow{2}{*}{$\begin{array}{c}\text { RT } \\
\text { source }\end{array}$} & \multirow{2}{*}{$\begin{array}{l}\text { Dose (Gy)/ } \\
\text { Fractions }\end{array}$} & \multicolumn{2}{|c|}{ BED } & \multirow{2}{*}{$\begin{array}{c}\text { Follow-up } \\
\text { (months) }\end{array}$} & \multirow{2}{*}{$\begin{array}{l}\mathrm{LC} \\
(\%)\end{array}$} \\
\hline & & & & & $\alpha / \beta=3$ & $\alpha / \beta=10$ & & \\
\hline 8 & 19 & $57.9 \mathrm{~cm}^{3}$ & $\mathrm{X}$-ray & $24-48 / 4$ & $72-240$ & $38-106$ & 13.7 & 100 \\
\hline 21 & 16 & $4.0 \mathrm{~cm}$ & X-ray & $30-40 / 5$ & $90-147$ & $48-72$ & 19 & 100 \\
\hline 11 & 33 & $4.8 \mathrm{~cm}$ & X-ray & $26-42 / 1-3$ & $238-251$ & 94-101 & 24 & 97 \\
\hline 22 & 40 & $3.9 \mathrm{~cm}$ & $X$-ray & $21-48 / 3$ & 70-304 & $65-125$ & 18.7 & 92.7 \\
\hline 23 & 13 & $2.8 \mathrm{~cm}$ & X-ray & $60-70 / 10$ & $180-233$ & 96-119 & 48.3 & 92.3 \\
\hline 24 & 9 & $4.6 \mathrm{~cm}$ & $\mathrm{X}$-ray & $40 / 5$ & 147 & 72 & 26.7 & 89 \\
\hline 25 & 7 & $5.5 \mathrm{~cm}$ & $\mathrm{X}$-ray & $30-40 / 3-4$ & $130-173$ & $60-80$ & 49 & 85.7 \\
\hline 12 & 19 & $3.6 \mathrm{~cm}$ & Carbon ion & $66-80 / 12-16$ & $133-187$ & $90-120$ & 79.2 & 94.1 \\
\hline Present & 22 & $3.5 \mathrm{~cm}$ & Protons & $60-79.6 / 10-36$ & $133-211$ & $94-110$ & 35 & 100 \\
\hline
\end{tabular}

RT: Radiotherapy; BED: biologically effective dose; LC, local control; pts: patients.

present study using a $\mathrm{BED}_{10} \geq 90 \mathrm{~Gy}$ with a median followup of $\geq 2$ years were higher than $90 \%(11,12,23)$. Taking the previous reports of SBRT and particle beam therapy together, BED $_{10} \geq 90$ Gy may be necessary and high-dose RT using advanced technology can accomplish good local tumor control. We consider that our PBT results in RCC patients are similar to those of previous studies in terms of excellent local tumor control and safety.

On the other hand, an appropriate benchmark is necessary to determine the optimal dose fractionation schedule to obtain local tumor control while preserving renal function after hypofractionated RT, including PBT and SBRT, for RCC. Siva et al. stated in another systematic review that BED calculations may not be reliable for extremely hypofractionated RT, given that preclinical models do not account for such high doses per fraction (11). Shibamoto et al. suggested that correction of the errors associated with using the BED, estimated at 5-20\%, is necessary when used for SBRT (27). Thus, estimation methods alternative to the linear-quadratic model for determining local tumor control 
after SBRT for RCC, as well as other diseases, need to be determined via large-scale analyses, to validate the efficacy of RT for RCC as a primary treatment.

The major limitations of the study are its retrospective nature, the heterogeneity among the patient and tumor characteristics, use of a wide variety of dose fractionation schedules, and absence of a standardized follow-up schedule. Furthermore, aspects of the PBT plans such as the treatment margins and management of respiratory movement were not completely unified. Future prospective studies can provide more refined treatment results for PBT. Moreover, it is necessary to compare the outcomes of PBT with those of other treatments including SBRT to understand the indications for PBT for RCC patients ineligible for surgery.

\section{Conclusion}

As the first multi-institutional retrospective study of PBT for RCC patients in Japan, our results revealed that PBT yields acceptable OS and local control rates with a low risk of toxicity. PBT may be an optional local treatment for RCC patients who cannot undergo surgery.

\section{Conflicts of Interest}

The Authors declare that there are no conflicts of interest with regard to the present study.

\section{Authors' Contributions}

Conception: NF and HI. Acquisition of data: TA, HW, TO, YS, HI, and SS. Analysis and interpretation of data: NF, HI, TA, HW, TO, YS, and HI. Writing: NF. Review and revision: HI, SS, and HS. Supervision: HS.

\section{References}

1 Cancer Registry and Statistics. Cancer Information Service, National Cancer Center, Japan Available at: https://ganjoho.jp/ reg_stat/statistics/dl/index.html\#incidence4pref [Last accessed on 2nd June 2020]

2 Motzer RJ, Jonasch E, Agarwal N, Bhayani S, Bro WP, Chang SS, Choueiri TK, Costello BA, Derweesh IH, Fishman M, Gallagher TH, Gore JL, Hancock SL, Harrison MR, Kim W, Kyriakopoulos C, LaGrange C, Lam ET, Lau C, Michaelson MD, Olencki T, Pierorazio PM, Plimack ER, Redman BG, Shuch B, Somer B, Sonpavde G, Sosman J, Dwyer M and Kumar R: Kidney Cancer, Version 2.2017, NCCN Clinical Practice Guidelines in Oncology. J Natl Compr Canc Netw 15(6): 804834, 2017. PMID: 28596261. DOI: 0.6004/jncen.2017.0100

3 Ljungberg B, Bensalah K, Canfield S, Dabestani S, Hofmann F, Hora M, Kuczyk MA, Lam T, Marconi L, Merseburger AS, Mulders P, Powles T, Staehler M, Volpe A and Bex A: EAU guidelines on renal cell carcinoma: 2014 update. Eur Urol 67(5): 913-924, 2015. PMID: 25616710. DOI: 10.1016/j.eururo.2015. 01.005
4 Zagoria RJ, Hawkins AD, Clark PE, Hall MC, Matlaga BR, Dyer RB and Chen MY: Percutaneous CT-guided radiofrequency ablation of renal neoplasms: factors influencing success. AJR Am J Roentgenol 183(1): 201-207, 2004. PMID: 15208139. DOI: 10.2214/ajr.183.1.1830201

5 Kunkle DA and Uzzo RG: Cryoablation or radiofrequency ablation of the small renal mass: a meta-analysis. Cancer 113(10): 2671-2680, 2008. PMID: 18816624. DOI: 10.1002/ cncr.23896

6 Ponsky LE, Crownover RL, Rosen MJ, Rodebaugh RF, Castilla EA, Brainard J, Cherullo EE and Novick AC: Initial evaluation of Cyberknife technology for extracorporeal renal tissue ablation. Urology 61(3): 498-501, 2003. PMID: 12639631. DOI: 10.1016/s0090-4295(02)02442-1

7 Teh BS, Bloch C, Paulino AC, Shen S, Hinckley L, Baskin D, Butler EB and Amato R: Pathologic complete response in renal cell carcinoma brain metastases treated with stereotactic radiosurgery. Clin Genitourin Cancer 5(5): 334-337, 2007. PMID: 17645831. DOI: 10.3816/CGC.2007.n.013

8 Ponsky L, Lo SS, Zhang Y, Schluchter M, Liu Y, Patel R, Abouassaly R, Welford S, Gulani V, Haaga JR, Machtay M and Ellis RJ: Phase I dose-escalation study of stereotactic body radiotherapy (SBRT) for poor surgical candidates with localized renal cell carcinoma. Radiother Oncol 117(1): 183-187, 2015. PMID: 26362723. DOI: 10.1016/j.radonc.2015.08.030

9 Siva S, Jackson P, Kron T, Bressel M, Lau E, Hofman M, Shaw M, Chander S, Pham D, Lawrentschuk N, Wong LM, Goad J and Foroudi E: Impact of stereotactic radiotherapy on kidney function in primary renal cell carcinoma: Establishing a doseresponse relationship. Radiother Oncol 118(3): 540-546, 2016. PMID: 26873790. DOI: 10.1016/j.radonc.2016.01.027.

10 Correa RJM, Louie AV, Zaorsky NG, Lehrer EJ, Ellis R, Ponsky L, Kaplan I, Mahadevan A, Chu W, Swaminath A, Hannan R, Onishi H, Teh BS, Muacevic A, Lo SS, Staehler M and Siva S: The emerging role of stereotactic ablative radiotherapy for primary renal cell carcinoma: a systematic review and metaanalysis. Eur Urol Focus 5(6): 958-969, 2019. PMID: 31248849. DOI: 10.1016/j.euf.2019.06.002

11 Siva S, Pham D, Gill S, Corcoran NM and Foroudi F: A systematic review of stereotactic radiotherapy ablation for primary renal cell carcinoma. BJU Int 110(11 Pt B): E737-743, 2012. PMID: 23107102. DOI: 10.1111/j.1464-410X.2012.11550.x

12 Kasuya G, Tsuji H, Nomiya T, Makishima H, Haruyama Y, Kobashi G, Ebner DK, Hayashi K, Omatsu T, Kishimoto R, Yasuda S, Igarashi T, Oya M, Akakura K, Suzuki H, Ichikawa T, Shimazaki J and Kamada T; Working Group for Genitourinary Tumors: Updated long-term outcomes after carbon-ion radiotherapy for primary renal cell carcinoma. Cancer Sci 109(9): 2873-2880. 2018. PMID: 29981249. DOI: 10.1111/cas.13727

13 Royce TJ and Efstathiou JA: Proton therapy for prostate cancer: A review of the rationale, evidence, and current state. Urol Oncol 37(9): 628-636. 2019. PMID: 30527342. DOI: 10.1016/ j.urolonc.2018.11.012

14 Apisarnthanarax S, Bowen SR and Combs SE: Proton beam therapy and carbon ion radiotherapy for hepatocellular carcinoma. Semin Radiat Oncol 28(4): 309-320, 2018. PMID: 30309641. DOI: 10.1016/j.semradonc.2018.06.008

15 Leroy R, Benahmed N, Hulstaert F, Van Damme N and De Ruysscher D: Proton therapy in children: a systematic review of clinical effectiveness in 15 pediatric cancers. Int J Radiat Oncol 
Biol Phys 95(1): 267-278, 2016. PMID: 27084646. DOI: $10.1016 /$ j.ijrobp.2015.10.025

16 Holliday EB and Frank SJ: Proton radiation therapy for head and neck cancer: a review of the clinical experience to date. Int J Radiat Oncol Biol Phys 89(2): 292-302, 2014. PMID: 24837890. DOI: 10.1016/j.ijrobp.2014.02.029

17 Yaes RJ, Patel P and Maruyama Y: On using the linear-quadratic model in daily clinical practice. Int $\mathrm{J}$ Radiat Oncol Biol Phys 20(6): 1353-1362, 1991. PMID: 2045309. DOI: 10.1016/03603016(91)90249-4

18 Eisenhauer EA, Therasse P, Bogaerts J, Schwartz LH, Sargent D, Ford R, Dancey J, Arbuck S, Gwyther S, Mooney M, Rubinstein L, Shankar L, Dodd L, Kaplan R, Lacombe D and Verweij J: New response evaluation criteria in solid tumours: revised RECIST guideline (version 1.1). Eur J Cancer 45(2): 228-247, 2009. PMID: 19097774. DOI: 10.1016/j.ejca.2008.10.026

19 Common terminology criteria for adverse events (CTCAE) Version 4.03. US Department of Health and Human Services, National Cancer Institute 2010. Available at: https://evs.nci. nih.gov/ftp1/CTCAE/CTCAE_4.03/CTCAE_4.03_2010-0614_QuickReference_5x7.pdf [Last accessed on 26 ${ }^{\text {th }}$ May, 2020]

20 Siva S, Louie AV, Warner A, Muacevic A, Gandhidasan S, Ponsky L, Ellis R, Kaplan I, Mahadevan A, Chu W, Swaminath A, Onishi H, Teh B, Correa RJ, Lo SS and Staehler M: Pooled analysis of stereotactic ablative radiotherapy for primary renal cell carcinoma: A report from the International Radiosurgery Oncology Consortium for Kidney (IROCK). Cancer 124(5): 934-942, 2018. PMID: 29266183. DOI: 10.1002/cncr.31156

21 Chang JH, Cheung P, Erler D, Sonier M, Korol R and Chu W: Stereotactic ablative body radiotherapy for primary renal cell carcinoma in nonsurgical candidates: initial clinical experience. Clin Oncol 28(9): e109-114, 2016. PMID: 27131756. DOI: 10.1016/j.clon.2016.04.002

22 Sun MR, Brook A, Powell MF, Kaliannan K, Wagner AA, Kaplan ID and Pedrosa I: Effect of stereotactic body radiotherapy on the growth kinetics and enhancement pattern of primary renal tumors. AJR Am J Roentgenol 206(3): 544-553, 2016. PMID: 26901010. DOI: 10.2214/AJR.14.14099
23 Funayama S, Onishi H, Kuriyama K, Komiyama T, Marino K, Araya M, Saito R, Aoki S, Maehata Y, Nonaka H, Tominaga L, Muramatsu J, Nakagomi H, Kamiyama M and Takeda M: Renal cancer is not radioresistant: slowly but continuing shrinkage of the tumor after stereotactic body radiation therapy. Technol Cancer Res Treat 18: 1533033818822329, 2019. PMID: 30803362. DOI: $10.1177 / 1533033818822329$.

24 Beitler JJ, Makara D, Silverman P and Lederman G: Definitive, high-dose-per-fraction, conformal, stereotactic external radiation for renal cell carcinoma. Am J Clin Oncol 27(6): 646-648, 2004. PMID: 15577450. DOI: 10.1097/01.coc.0000145289.57705.07

25 Svedman C, Karlsson K, Rutkowska E, Sandström P, Blomgren H, Lax I and Wersäll P: Stereotactic body radiotherapy of primary and metastatic renal lesions for patients with only one functioning kidney. Acta Oncol 47(8):1578-1583, 2008. PMID: 18607859. DOI: 10.1080/02841860802123196

26 Svedman C, Sandstrom P, Pisa P, Blomgren H, Lax I, Kälkne KM, Nilsson S and Wersäll P: A prospective Phase II trial of using extracranial stereotactic radiotherapy in primary and metastatic renal cell carcinoma. Acta Oncol 45(7): 870-875, 2006. PMID: 16982552 . DOI: 10.1080/02841860600954875

27 Shibamoto Y, Miyakawa A, Otsuka S and Iwata H: Radiobiology of hypofractionated stereotactic radiotherapy: what are the optimal fractionation schedules? J Radiat Res 57(Suppl 1): i76i82, 2016. PMID: 27006380. DOI: 10.1093/jrr/rrw015
Received June 2, 2020

Revised June 27, 2020

Accepted June 29, 2020 